found glucose absorption rate in the proximal intestine to be $12 \mathrm{mmol} / \mathrm{hr} / 10 \mathrm{mg}$ dry weight and in the distal intestine to be $4 \mathrm{mmol} / \mathrm{hr} / 10 \mathrm{mg}$ dry weight. From a similar solution (56 $\mathrm{mM}$ ), the rate of absorption in the present study was approximately $18 \mathrm{mmol} / \mathrm{hr} / 10 \mathrm{mg}$ dry weight of the jejunum + ileum. Rider et al. (11), in perfusion studies of the proximal intestine, found rate of absorption of glucose to be about 10 $\mathrm{mg} / \mathrm{hr} / 10 \mathrm{~cm}$. In the present study, rate of absorption from a solution with a similar mean glucose concentration was 8 $\mathrm{mg} / \mathrm{hr} / 10 \mathrm{~cm}$ of the perfused jejunum + ileum.

\section{SUMMARY}

In vivo study of $\mathrm{D}$-glucose absorption in small intestine of rats between 7 and 73 days of age suggested that rate of absorption normalized for intestinal weight increased twofold at the time of weaning (21-23 days of age) with no further increase thereafter.

\section{REFERENCES AND NOTES}

1. Altmann, G, G., and Enesco, M.: Cell number as a measure of distribution and renewal of epithelial cells in the small intestine of growing and adult rats. Amer. J. Anat., 121:319-336 (1967).

2. Cori, C. F.: The fate of sugar in the animal body. I. The rate of absorption of hexoses and pentoses from the intestinal tract. J. Biol. Chem., 66: 691-715 (1925).

3. Dahlqvist, A.: Assay of intestinal disaccharidases. Ann. Biochem., 22: 99-107 (1968).

4. Herbst, J. J., and Sunshine, P.: Postnatal development of the small intestine of the rat. Pediat. Res. 3: 27-33 (1969).

5. Huggett, A. St. G.; and Nixon, D.: Enzymic determination of blood glucose. Biochem. J., 66: 12P (1957).

6. Koldovsky, O.: Development of Functions of the Small Intestine in Mammals and Man, p. 63. (S. Karger, Basel, 1969).

7. Koldovsky, O.: Hormonal and dietary factors in the development of digestion and absorption. In: M. Winick: Nutrition and

Copyright (C) 1975 International Pediatric Research Foundation, Inc.
Development (John Wiley \& Sons, Inc., New York, 1972)

8. Miller, D. L.: Rat small intestine: Development, composition and effects of perfusion. Amer. J. Dig. Dis. 16: 247-254 (1971).

9. Powell, D. W., and Malawer, S. J.: Relationship between water and solute transport from isosmotic solutions by rat intestine in vivo. Amer. J. Physiol., 215: 49-55 (1968).

10. Powell, D. W., Plotkin, G. R., Solberg, L. I., Catlin, D. H., Maenza, R. M., and Formal, S. B.: Experimental diarrhea. II. Glucosestimulated sodium and water transport in rat salmonella enterocolitis. Gastroenterology, 60: 1065-1075 (1971).

11. Rider, A. K., Schedl, H. P., Nokes, G., and Shining, S.: Small intestinal glucose transport. J. Gen. Physiol., 50: 1173-1182 (1967).

12. Schedl, H. P., and Clifton, J. A.: Small intestinal absorption of steroids. Gastroenterology, 41: 491 -499 (1965).

13. Verzar, F., and McDougall, E. J.: Absorption from the Intestine. (Longmans, Green \& Co., London, 1936).

14. Younoszai, M. K. and Ranshaw, J. C.: Gastrointestinal growth in normal male and female rats. Growth, 38: 225-235 (1974).

15. Younoszai, M. K., and Lynch, A.: In vivo intestinal absorption of hexose in growth-retarded suckling rat pups. J. Nutr., 104: 671-677 (1974).

16. Younoszai, M. K.: Jejunal absorption of hexose in infants and adult. J. Pediat., 85: 446 (1974).

17. Holtzman Co., Madison, Wisc.

18. Wayne Lab Blox, Allied Mills, Chicago, Ill.

19. Paper chromatography showed no contamination by other hexoses or disaccharides. No starch could be detected.

20. Fisher Scientific Co., Fairlawn, N. J.

21. Harvard Apparatus no. 1201, Harvard Apparatus Co., Millis, Mass.

22. Dr. M. K. Younoszai is a recipient of National Institutes of Health Academic Career Development Award AM 70211 in Digestive Diseases-Nutrition.

23. This research was supported in part by Nutrition Foundation Grant no. 451 and Research Grant HD 08227; Department of Child Health and Human Development, National Institutes of Health.

24. Requests for reprints should be addressed to: M. K. Younoszai, M.D., Department of Pediatrics, University of Iowa Hospitals and Clinics, The University of Iowa, Iowa City, Iowa 52242 (USA). 25. Accepted for publication November 12, 1974.

Printed in U.S.A.

Pediat. Res. 9: 133-138 (1975)

\title{
Production of the Features of Reye's Syndrome in Rats with 4-Pentenoic Acid
}

\author{
ALLEN M. GLASGOW ${ }^{(35)}$ AND H. PETER CHASE \\ University of Colorado Medical Center, Department of Pediatrics, Denver, Colorado, USA
}

Extract

4-Pentenoic acid, an analog of hypoglycin which is believed to cause Jamaican vomiting sickness, was administered intraperitoneally to rats in an attempt to produce the features of Reye's syndrome in rats. Mean ammonia levels in plasma were found to be elevated approximately four-fold after injection of $200 \mathrm{mg} / \mathrm{kg}$ pentenoic acid in fed rats. Pentenoic acid caused hypoglycemia in fasted rats and hyperglycemia in fed rats. In chronic experiments rats were injected intraperitoneally every $4 \mathrm{hr}$ with $50 \mathrm{mg} / \mathrm{kg}$ body weight of pentenoic acid for 10 doses, followed by a single dose of $200 \mathrm{mg} / \mathrm{kg}$. The livers of the treated group were enlarged and yellow and showed extensive fatty degeneration. The blood-urea-nitrogen (BUN) was significantly higher and the free fatty acids (FFA's) significantly lower in these rats. This study shows that pentenoic acid administered to rats produces findings similar to those of Reye's syndrome and Jamaican vomiting sickness.

\section{Speculation}

The similarity of the features of Reye's syndrome, Jamaican vomiting sickness, and pentenoic acid and hypoglycin toxicity 
suggests that they may be related, perhaps sharing a common pathophysiology.

Reye's syndrome was first defined as a clinicopathologic entity in 1963 (16), and usually presents as encephalopathy with evidence of hepatic dysfunction in children. The most consistent pathologic findings are fatty degeneration of the viscera, especially the liver, and cerebral edema. Common laboratory findings include hypoglycemia, elevated ammonia, and serum transaminases and a prolonged prothrombin time (8). It is relatively common, with $10-20$ cases seen/year in Denver. The cause is unknown. One of the factors limiting the study of the pathophysiology and treatment of Reye's syndrome is the lack of a well defined experimental model. A preliminary account of a model, involving the toxicity of octanic acid in rabbits, has appeared (28).

Jamaican vomiting sickness is characterized by vomiting, encephalopathy, hypoglycemia and fatty degeneration of the viscera $(10,13,18)$. It is thought to be caused by ingestion of the ackee fruit which contains a toxic compound, hypoglycin (3). Most of the evidence for a causal relation rests on the fact that hypoglycin and related chemicals produce a similar syndrome in laboratory animals $(3,9)$.

We were impressed with the similarity of Jamaican vomiting sickness and Reye's syndrome. Because of the unavailability of hypogly cin, a related compound, 4-pentenoic acid (Scheme 1), hereafter referred to as pentenoic acid, was used in the present experiments in an attempt to produce the features of Reye's syndrome in rats. This study shows that pentenoic acid administered to rats produces findings quite similar to those of Reye's syndrome.

\section{METHODS AND MATERIALS}

Male Sprague-Dawley rats weighing 200-330 g were maintained on commercial rat chow (30). At the time of the experiment, rats were transferred to individual wire-bottom cages and food, but not water, was removed for the duration of the experiment. At the start, control and test rats were paired to within $10 \mathrm{~g}$ body weight and similar treatment was maintained throughout in that injections, sample collections, and biochemical determinations were always done on the pair at the same time.

Initial experiments were performed with pentenoic acid (31) that had been neutralized without prior purification with $5 \mathrm{M}$ $\mathrm{NaOH}$ to $\mathrm{pH} 7.4 \pm 0.1$. It was later found by gas liquid chromatography and mass spectrometry that there was a substantial (roughly 10\%) contamination. Subsequently, pentenoic acid was purified by dissolving it in ether, making the sodium salt by the slow addition of an equimolar amount of $\mathrm{NaH}$, and twice recrystallizing the product from methanol with the slow addition of ether. The product was essentially

$$
\begin{gathered}
\mathrm{CH}_{2}=\mathrm{C}-\mathrm{CH}-\mathrm{CH}_{2}-\mathrm{CH}-\mathrm{COO}^{-} \\
\text {Hypoglycin } \\
\mathrm{CH}_{2}=\mathrm{C}_{-}-\mathrm{CH}_{2}-\mathrm{CH}_{2}-\mathrm{COO}^{-}
\end{gathered}
$$

Methylene-cyclopropyl acetic acid (active metabolite of hypoglycin)

$$
\begin{aligned}
\mathrm{CH}_{2}= & \mathrm{CH}-\mathrm{CH}_{2}-\mathrm{CH}_{2}-\mathrm{COO}^{-} \\
& \text {4-Pentenoic acid }
\end{aligned}
$$

Scheme 1 free from contamination in the same chromatography system. Inasmuch as purified and unpurified pentenoic acid gave similar results, the data were combined. In all cases, pentenoic acid was made up to a concentration of $50 \mathrm{mg} / \mathrm{cc}$ (based on the weight of the free acid) and passed through a $0.45-\mu \mathrm{m}$ Millipore filter. Controls received an equal volume of $0.5 \mathrm{M}$ $\mathrm{NaCl}$.

Preliminary experiments showed pentenoic acid has a relatively short duration of action. Because some of the abnormalities might be expected to be present only in acutely ill rats (e.g., elevated ammonia, hypoglycemia), whereas other alterations might occur only over a longer time period (e.g., fatty liver, elevated BUN), models for acute and chronic toxicity were developed.

In the acute experiments rats were given one dose of 200 $\mathrm{mg} / \mathrm{kg}$ pentenoic acid intraperitoneally and a short time later (specified in figures) samples were collected. In chronic experiments rats were injected intraperitoneally every $4 \mathrm{hr}$ with $50 \mathrm{mg} / \mathrm{kg}$ body weight of pentenoic acid for 10 doses. One to $2 \mathrm{hr}$ after the last $50 \mathrm{mg} / \mathrm{kg}$ dose, $200 \mathrm{mg} / \mathrm{kg}$ were given intraperitoneally and samples collected $20-45 \mathrm{~min}$ later.

For sample collection, rats were anesthetized with ether, their abdomens opened, and blood collected from the abdominal aorta. In chronic experiments, the total body weight and the liver weight were measured and tissue placed in $10 \%$ formalin for histologic examination. Appropriate sections were stained with hematoxylin and eosin (H \& E) and osmic acid stains.

Serum glucose, glutamic oxaloacetic transaminase (SGOT), $\mathrm{Na}^{+}, \mathrm{BUN}$, and bilirubin were determined as described previously (15). Blood gases were measured using a blood gas analyzer (32). Ammonia in plasma was measured using a commercial ammonia kit (33). Free fatty acids were estimated by the method of Novak (14).

Differences were tested for significance by the paired $t$ test (17).

\section{RESULTS}

Formal testing of the $\mathrm{LD}_{50}$ was not done. However, some rats given $100 \mathrm{mg} / \mathrm{kg}$ pentenoic acid died within $2 \mathrm{hr}$. Other animals given this dose progressed to the stage of prostration and recovered after $2 \mathrm{hr}$, and thereafter appeared normal. At a dose of $200 \mathrm{mg} / \mathrm{kg}$ all rats died, fed rats in $20-30 \mathrm{~min}$ and fasted rats in 45-60 min. The first noticeable sign of toxicity was increased depth of respirations, followed by prostration and then seizures, coma, and death.

\section{ACUTE STUDIES}

Acute studies were done in both fed and fasted rats. Mean plasma ammonia levels were found to be elevated approximately fourfold after the injection of $200 \mathrm{mg} / \mathrm{kg}$ pentenoic acid in fed rats (Fig. 1). Two fasted rats treated acutely with purified pentenoic acid had levels of ammonia in plasma of 249 and $281 \mu \mathrm{g} / 100 \mathrm{ml}$ and the respective controls had levels of 42 and $45 \mu \mathrm{g} / 100 \mathrm{ml}$. Pentenoic acid caused hypoglycemia in fasted rats (Fig. 3) and hyperglycemia in fed rats (Fig. 1). There was a suggestion that FFA's were elevated in the fasted animals given pentenoic acid, but the differences were not statistically significant (Fig. 2). Blood gases were measured in eight rats (Table 1). Three treated rats had a mild acidosis, with $\mathrm{CO}_{2}$ retention in two of these. In agreement with our observation of hyperventilation, four test rats had a $\mathrm{pH}$ higher than all control rats and relatively low $\mathrm{P}_{\mathrm{CO}_{2}}$ values.

\section{CHRONIC STUDIES}

Rats treated chronically with pentenoic acid showed no obvious signs of illness until after the last dose of $200 \mathrm{mg} / \mathrm{kg}$. Treated rats lost significantly more weight $(P<0.001)$ than 


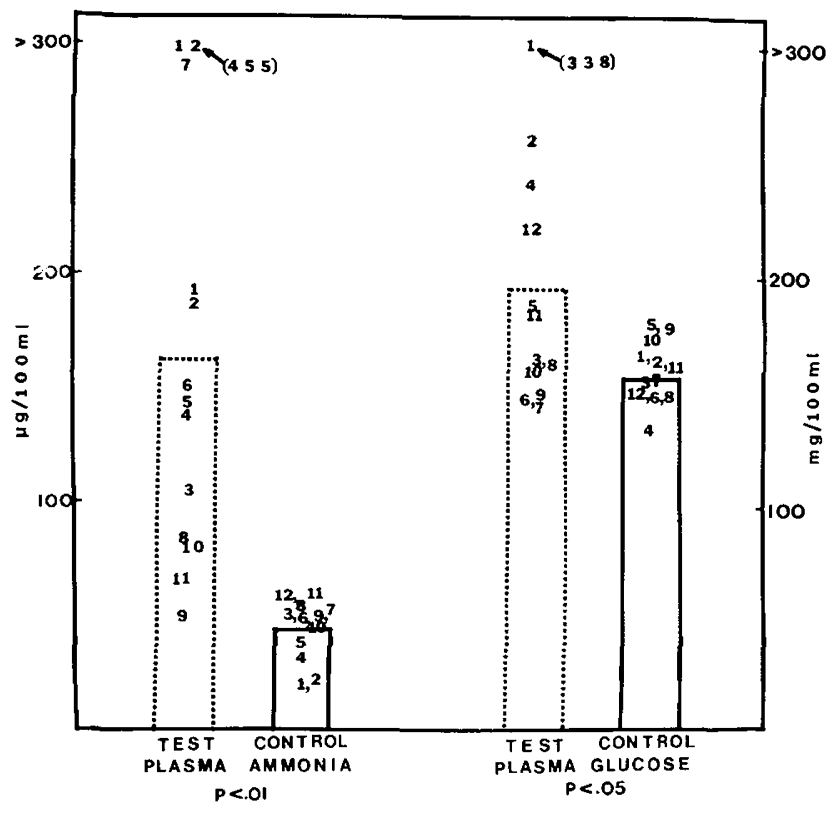

Fig. 1. Acute treatment in fed rats. Rats that had been allowed free access to food were given $200 \mathrm{mg} / \mathrm{kg}$ pentenoic acid and $20-25 \mathrm{~min}$ later samples were collected. The numbers refer to the pair number. Rats $7-12$ were given purified pentenoic acid. Twelve pairs of rats were studied.

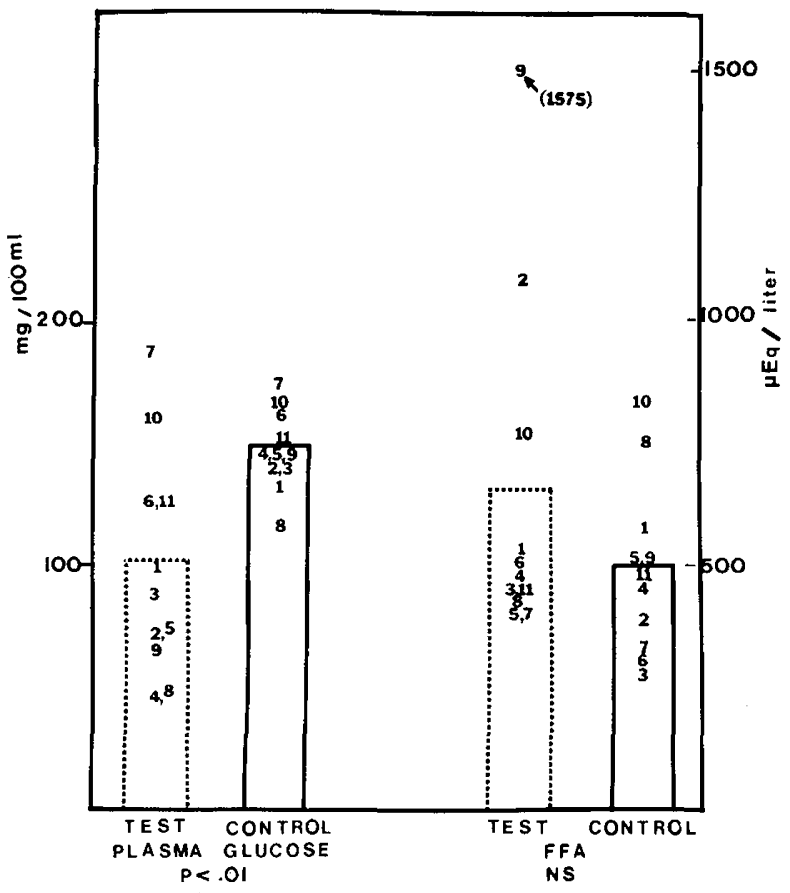

Fig. 2. Acute treatment in fasted rats. Rats that had been fasted for $20 \mathrm{hr}$ were given $200 \mathrm{mg} / \mathrm{kg}$ pentenoic acid and 45-60 min later, as soon as the rats began having seizures, samples were collected. The numbers refer to the pair number. Rats $7-11$ were given purified pentenoic acid. Eleven pairs of rats were studied.

control rats. The treated group lost $18.2 \pm 1.8 \%$ (1 SD) initial body weight (mean weight loss $43 \pm 5.7 \mathrm{~g}$ ) and the control group $15.3 \pm 2.1 \%$ initial body weight (mean weight loss $36 \pm$ $8.2 \mathrm{~g}$ ) from an initial mean weight of $236 \mathrm{~g}$ in both groups.

The livers of the treated group were enlarged on gross inspection and weighed more than the livers of the controls ( $P$ $<0.001)$. The mean ( \pm 1 SD) percentage of initial body weight was $3.17 \pm 0.41 \%$ for test livers (actual mean weight $=7.49 \mathrm{~g}$ ) compared with $2.48 \pm 0.15 \%$ for control livers (actual mean weight $5.87 \mathrm{~g}$ ).
Figure 3 shows an $\mathrm{H} \&$ E-stained section of liver from typical control and test rats and a similarly prepared section from a patient with Reye's syndrome for comparison. The livers from the pentenoic acid-treated rats showed extensive fatty degeneration. The fat was distributed in small droplets throughout the cellular cytoplasm, with no displacement of the nucleus. Individual hepatocytes were enlarged and nucleoli were prominent. There was no evidence of necrosis, inflammation, or bile stasis.

In the chronic experiments there was no significant difference between the glucose in plasma in the control and experimental groups, although the glucose in two treated rats was clearly low $(91$ and $106 \mathrm{mg} / 100 \mathrm{ml}$ ). Chronic treated rats were killed before they had seizures, in contrast to the acutely treated fasted rats. The SGOT activity was statistically, elevated when both the rats given the unpurified and purified pentenoic acid were compared with controls. The SGOT was higher, but not significantly so, in the five rats given purified pentenoic acid compared with their paired controls. The BUN was signficantly higher in the treated rats and the FFA's lower than in control rats (Fig. 4).

The mean serum sodium in both the test and control groups was $142 \mathrm{mEq} / \mathrm{liter}$. The total bilirubin was measured (to the nearest $0.1 \mathrm{mg} / 100 \mathrm{ml}$ ) in 10 pairs and was $0.1 \mathrm{mg} / 100 \mathrm{ml}$ in nine treated and nine control rats and $0.3 \mathrm{mg} / 100 \mathrm{ml}$ in one test and one control rat.

\section{DISCUSSION}

The present study shows that pentenoic acid produces in rats most of the essential features of Reye's syndrome. Table 2 combines the data from the present paper and previous reports and shows a striking similarity between Reye's syndrome, Jamaican vomiting sickness, and findings produced in animals by hypoglycin or pentenoic acid.

The elevated ammonia in the pentenoic acid-treated rats presumably reflects inhibition of hepatic ureagenesis. The fact that the serum ammonia rises fourfold only 20-25 min after the injection of pentenoic acid illustrates the rapid turnover of ammonia in relation to the plasma level. Since there is no clear relation between plasma ammonia levels and the resultant encephalopathy, the role of the elevated ammonia in the toxicity of pentenoic acid is not established, but should receive consideration as a possible factor.

Hypoglycemia from pentenoic acid occurred only in fasted rats, and could be consistently demonstrated only shortly before death. Pentenoic acid probably causes hypoglycemia by inhibiting gluconeogenesis (see below), and thus the lack of

Table 1. Acute treatment in fed rats

\begin{tabular}{|c|c|c|c|c|c|c|c|c|}
\hline & \multicolumn{2}{|c|}{$\mathrm{pH}$} & \multicolumn{2}{|c|}{$\mathrm{P}_{\mathrm{O}_{2}}$} & \multicolumn{2}{|c|}{$\mathrm{P}_{\mathrm{CO}_{2}}$} & \multicolumn{2}{|c|}{ Base excess } \\
\hline & $\mathrm{P}$ & $\mathrm{C}$ & $\mathbf{P}$ & $\mathrm{C}$ & $\mathbf{P}$ & $\mathrm{C}$ & $\mathrm{P}$ & $\mathrm{C}$ \\
\hline 1 & $7.39^{2}$ & 7.48 & $26^{2}$ & 81 & $41^{2}$ & 30 & $0^{2}$ & 0 \\
\hline 2 & 7.52 & 7.51 & 85 & 85 & 26 & 27 & 0 & 0 \\
\hline 3 & 7.50 & 7.48 & 84 & 76 & 29 & 30 & 0 & 0 \\
\hline 4 & 7.52 & 7.49 & 81 & 76 & 20 & 29 & -4 & 0 \\
\hline 5 & 7.42 & 7.50 & 86 & 67 & 21 & 26 & -10 & -1 \\
\hline 6 & 7.53 & 7.47 & 70 & 64 & 25 & 30 & 0 & 0 \\
\hline $7^{3}$ & 7.54 & 7.45 & 80 & 54 & 28 & 34 & +2 & 0 \\
\hline $8^{3}$ & 7.44 & 7.45 & 50 & 74 & 40 & 30 & +3 & -2 \\
\hline
\end{tabular}

${ }^{1}$ Rats that had been allowed free access to food were given 200 $\mathrm{mg} / \mathrm{kg}$ pentenoic acid and $20-25$ min later samples were collected; $\mathbf{P}$ : pentenoic acid; $\mathrm{C}$ : control.

${ }^{2}$ Values obtained from animals that were barely gasping. The other animals manifest only hyperventilation.

${ }^{3}$ Purified pentenoic acid. 

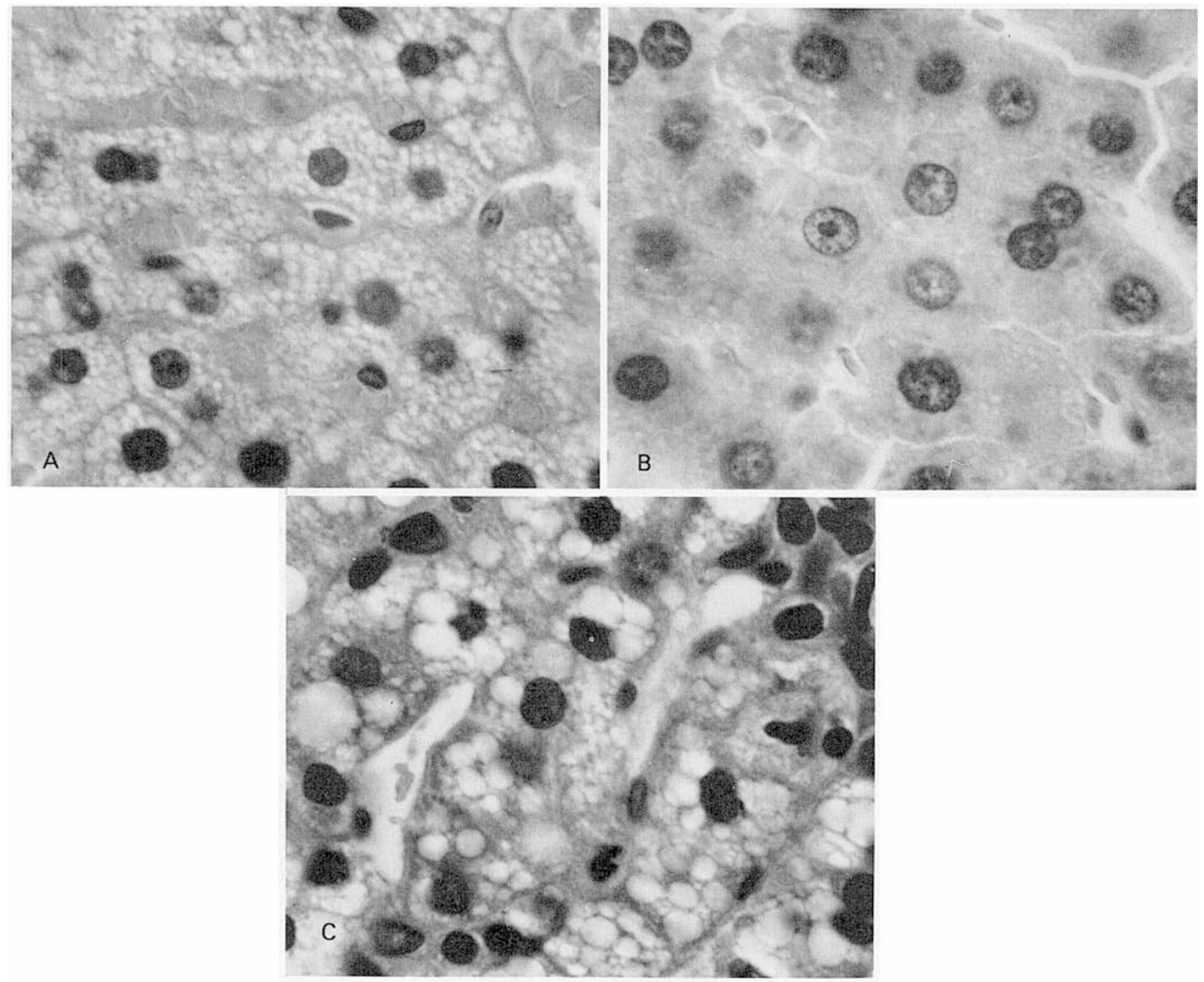

Fig. 3. Hematoxylin and eosin-stained sections of liver from test $(A)$ and control rats $(B)$ and a patient with Reye's syndrome $(C)$. Original magnification $\times 650$.

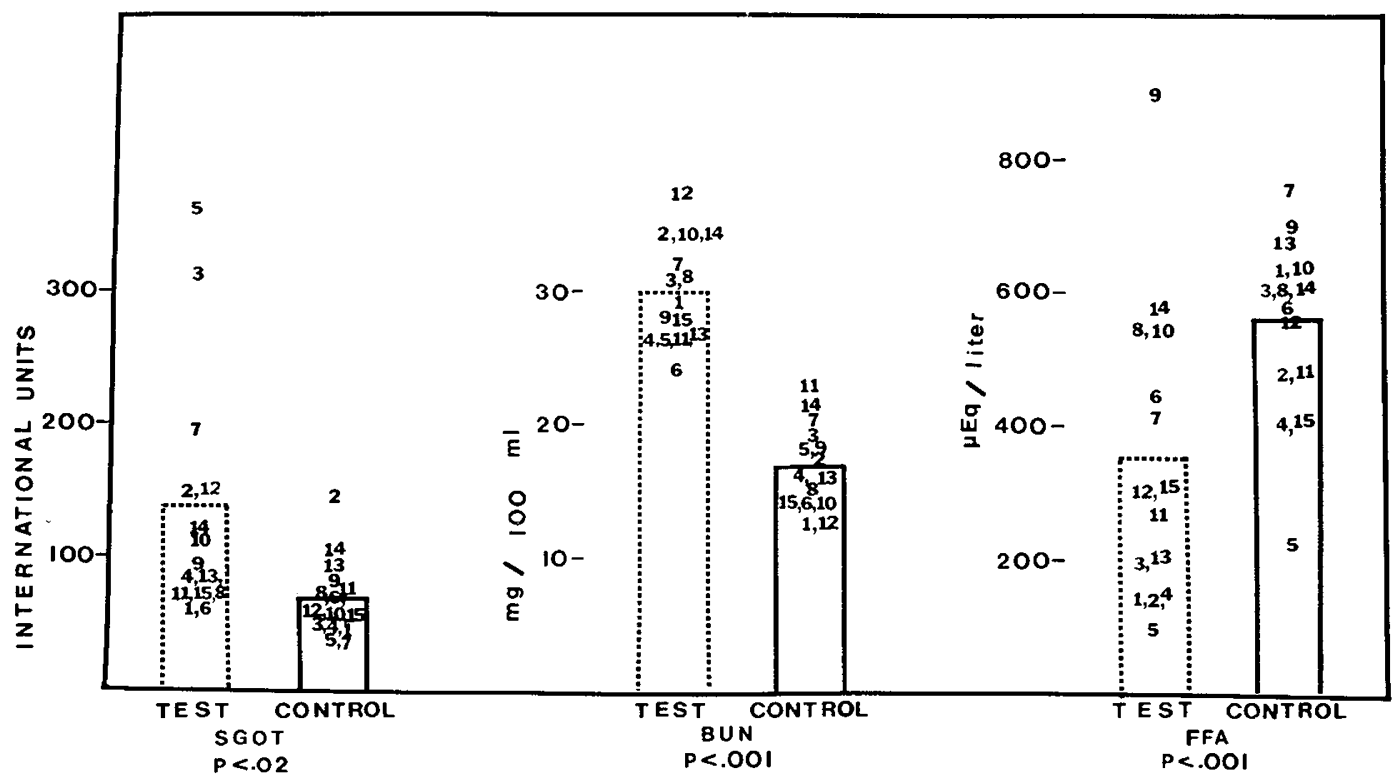

Fig. 4. Chronic treatment. See Methods for dosage schedule. The numbers refer to the pair number. Rats $11-15$ were given purified pentenoic acid. Rats 6-10 were killed $45 \mathrm{~min}$ after the $200 \mathrm{mg} / \mathrm{kg}$ dose. All others were killed $20 \mathrm{~min}$ after this dose. Fifteen pairs of rats were studied. 
Table 2. Comparison of Reye's syndrome, Jamaican vomiting sickness, hypoglycin, and pentenoic acid poisoning

\begin{tabular}{|c|c|c|c|c|}
\hline Vomiting common & Yes & Yes (18) & Yes (3) & \\
\hline Children primarily affected & Yes & Yes (18) & & \\
\hline Hypoglycemia common & Yes & Yes $(10,13)$ & Yes (3) & Yes $^{1}(22)$ \\
\hline Rapid Response to glucose uncommon & Yes & Yes (13) & Yes (3) & \\
\hline Elevated ammonia & Yes & & & Yes $^{1}$ \\
\hline Elevated $\mathrm{BUN}^{2}$ & Yes & & Yes (3) & Yes $^{1}$ \\
\hline Bilirubin usually normal & Yes & Yes $(10,13)$ & & Yes $^{1}$ \\
\hline Fatty infiltration of liver & Yes & Yes $(10,18)$ & Yes $(9)$ & Yes $^{1}$ \\
\hline Hepatic mitochondrial swelling & Yes & & Yes (4) & \\
\hline Cerebral edema & Yes & Yes $(10)$ & & \\
\hline
\end{tabular}

${ }^{1}$ Present paper.

2 Blood-urea-nitrogen.

hypoglycemia in fed rats is not unexpected. The fact that the fed rats were hyperglycemic indicates that factors other than hypoglycemia are important in the toxicity of pentenoic acid.

The elevated urea in the pentenoic acid-treated rats may be caused by dehydration, impaired renal function, or increased utilization of amino acids for energy. The former seems least likely since the weight difference between test and control rats would indicate at most about 3\% dehydration in the test rats.

Some workers have suggested that elevated FFA's may be important in the pathophysiology of Reye's syndrome $(5,6)$. Thus the low free fatty acids in the rats given the chronic pentenoic acid treatment might be interpreted as an important difference between pentenoic acid toxicity and Reye's syndrome. We suspect that the level of FFA's is probably often a reflection of stress and hypoglycemia. The mean levels of FFA's of $2.41 \mathrm{mEq} / \mathrm{liter}$ in a group of patients with Reye's syndrome (1) are not markedly different from the mean level of $1.95 \mathrm{mEq} /$ liter in a group of normal children fed a ketogenic diet and fasted (23). The FFA's were higher (although not significantly so) in the acutely treated 20-hr fasted rats that were severely ill and hypoglycemic. In another study, a single dose of pentenoic acid did result in an apparent elevation of FFA's in rats fasted only $4 \mathrm{hr}$ (22). Elevated FFA's have been reported in hypoglycin-treated hypoglycemic rats (7). In the chronically treated rats in this study there was a suggestion that FFA's rise in response to stress. The five rats killed at $45 \mathrm{~min}$ after the $200 \mathrm{mg} / \mathrm{kg}$ dose (prostrate and hyperventilating) had mean FFA levels of 565 $\mathrm{mEq} /$ liter compared with a mean level of $240 \mathrm{mEq} /$ liter in rats killed at $20 \mathrm{~min}$ (not obviously ill). Thus chronic treatment of rats with pentenoic acid results in low FFA's but the level of FFA's probably rises in response to stress.

The SGOT in the pentenoic acid-treated rats was higher than in controls but was not statistically different for the group given purified pentenoic acid and was not of the magnitude often seen in Reye's syndrome. The meaning of this apparent difference between pentenoic acid toxicity and Reye's syndrome is not clear, since there is little basis for interpreting SGOT values in rats. In addition, even the apparent elevation that did occur could be caused by factors such as an irritative effect of pentenoic acid in the peritoneal cavity.

The similarity between this model and Reye's syndrome suggests that they may share a common pathophysiology. It is possible that Reye's syndrome is caused by exposure to pentenoic acid or a related compound. Although this possibility should not be completely discarded, it seems unlikely. More likely is the possibility that pentenoic acid-treated animals and patients with Reye's syndrome share the same or a similar biochemical defect or defects. Thus, it seems appropriate to review briefly what is known about the pathophysiology of the toxic effects of pentenoic acid.

Pentenoic acid is a potent inhibitor of fatty acid oxidation $(2,19)$. Bressler et al. (3) has proposed that this inhibition is caused by depletion of intracellular free CoA and carnitine; however, Sherrat and coworkers (12), using isolated mitochondria, have shown that there is no relation between the ability of related compounds to reduce mitochondria-free $\mathrm{CoA}$ and their ability to inhibit fatty acid oxidation. They have shown that a metabolite of pentenoic acid, 2,4-pentadienoyl-CoA, is a potent inhibitor of 3-oxoacyl-CoA-thiolase, an enzyme of fatty acid oxidation, and proposed this as the cause of the impaired fatty acid oxidation (11). In any case, one direct effect of pentenoic acid is interruption of fatty acid oxidation. At higher concentrations it also impairs other mitochondrial functions (20). Pentenoic acid results in decreased tissue ATP and NADH $(2,29)$.

The reduced availability of energy probably accounts for the decreased gluconeogenesis (24). Because fatty acids cannot be metabolized, there is increased use of glucose for energy. The impaired gluconeogenesis and, to some extent, increased glucose utilization results in hypoglycemia. The hypoglycemia thus is probably secondary to the direct effect of pentenoic acid on fatty acid oxidation (24). Presumably, since fatty acids cannot be oxidized they are esterified to triglycerides accounting for the fatty degeneration of the liver. It is not known whether the impairment of fatty acid oxidation accounts for all of the effects of pentenoic acid.

Tanaka et al. $(25-27)$ have shown that hypoglycin inhibits the enzyme isovaleryl-CoA dehydrogenase and probably also glutaryl-CoA dehydrogenase and in rats results in the excretion of isovaleric, glutaric, and several other unusual carboxylic acids. In this respect hypoglycin toxicity and probably Jamaican vomiting sickness differ from pentenoic acid toxicity and Reye's syndrome. For more details on pentenoic acid and related compounds the reader is referred to reviews by Bressler (3) and Sherratt (24).

\section{SUMMARY}

4-Pentenoic acid, an analog of hypoglycin which is believed to cause Jamaican vomiting sickness was administered to rats in an attempt to produce the features of Reye's syndrome. Pentenoic acid produced most of the essential features of this disorder, including fatty degeneration of the liver, hyperammoniaemia, hypoglycemia, and elevated SGOT and BUN levels. 


\section{REFERENCES AND NOTES}

1. Bourgeois, G., Olson, L., Comer, D., Evans, H., Keschamras, N., Cotton, R., Grossman, R., and Smith, T.: Encephalopathy and fatty degeneration of the viscera: A clinicopathologic analysis of 40 cases. Amer. J. Clin. Pathol., 56: 558 (1971).

2. Brendel, K., Corredor, C., and Bressler, R.: The effect of 4-pentenoic acid on fatty acid oxidation. Biochem. Biophys. Res. Commun., 34: 340 (1969).

3. Bressler, R., Corredor, C., and Brendel, K.: Hypoglycin and hy pogly cin-like compounds. Pharmacol. Rev., 21: 150 (1969).

4. Brooks, S. E. H., and Audretsch, J. J.: Studies on hypoglycin toxicity in rats. Amer. J. Pathol., 59: 161 (1970).

5. Brown, R. E., and Madge, G. E.: Pulmonary findings in Reye's syndrome. Arch. Pathol., 92: 475 (1971).

6. Brown, R. E., Madge, G. E., and Schiller, H. M.: Observations on the pathogenesis of Reye's syndrome. S. Med. J., 64: 942 (1971).

7. De Renzo, E. C., McKerns, K. W., Bird, H. H., Cekleniak, W. P., Coulomb, B., and Kaleita, E.: Some biochemical effects of hypoglycin. Biochem. Pharmacol., 1: 236 (1958).

8. Glasgow, A. M., Cotton, R. B., and Dhiensiri, K.: Reye's syndrome: Blood ammonia and consideration of the nonhistologic diagnosis. Amer. J. Dis. Child., 124: 827 (1972).

9. Hassall, C. H., and Reyle, K.: The toxicity of the Ackee (Blighia sapida) and its relationship to the vomiting sickness of Jamaica. W. Ind. Med. J., 4: 83 (1955).

10. Hill, K. R., Bras, G., and Clearkin, K. P.: Acute toxic hypoglycemia occurring in the vomiting sickness of Jamaica. W. Ind. Med. J., 4: 91 (1955).

11. Holland, P. C., Senior, A. E., and Sherratt, H. S. A.: Biochemical effects of the hypoglycemic compound pent-4-enoic acid and related non-hypoglycaemic fatty acids. Biochem. J., 136:173 (1973).

12. Holland, P. C., and Sherratt, H. S. A.: Biochemical effects of the hypoglycaemic compound pent-4-enoic acid and related nonhy poglycaemic fatty acids. Biochem. J., 136: 157 (1973).

13. Jelliffe, D. B., and Stuart, K. L.: Acute toxic hypoglycemia in the vomiting sickness of Jamaica. Brit. Med. J., 1: 75 (1954).

14. Novak, M.: Colorimetric ultra micro method for the determination of free fatty acids. J. Lipid Res., 6: 431 (1965).

15. O'Brien, D., Ibbott, F. A., and Rodgerson, D. O.: In: Laboratory Manual of Pediatric Micro-Biochemical Techniques, 4 th Ed. (Harper and Row, New York, 1968).

16. Reye, R. D. K., Morgan, G., and Baral, J.: Encephalopathy and fatty degeneration of the viscera, a disease entity in childhood. Lancet, ii: 749 (1963).

17. Remington, R. D., and Schork, M. A.: Statistics with Applications to the Biological and Health Sciences, p. 213 (Prentice-Hall, Inc.,
Englewood Cliffs, N. J., 1970).

18. Scott, H. H.: On the vomiting sickness of Jamaica. Ann. Trop. Med. Parasitol., 10: 1 (1916).

19. Senior, A. E., Robson, B., and Sherratt, H. S. A.: Biochemica effects of the hypoglycaemic compound pent-r-enoic acid and related non-hypoglycaemic fatty acids. Biochem. J., 110: 511 (1968).

20. Senior, A. E., and Sherratt, H. S. A.: Biochemical effects of the hypoglycemia compound pent-4-enoic acid and related non-hypoglycaemic fatty acids. Biochem. J., $110: 499$ (1968).

21. Senior, A. E., and Sherratt, H. S. A.: Biochemical effects of the hypoglycaemic compound pent-4-enoic acid and related nonhy poglycemic fatty acids. Biochem. J., 110:521 (1968).

22. Senior, A. E., and Sherratt, H. S. A.: A comparison of the effects on blood glucose and ketone-body levels, and of the toxicities, of pent-4-enoic acid and four simple fatty acids. J. Pharm. Pharmacol., 21: 85 (1969).

23. Senior, B., and Loridan, L.: Gluconeogenesis and insulin in the ketotic variety of childhood hypoglycemia and in control children. J. Pediat., 74: 529 (1969)

24. Sherratt, H. S. A.: Hypoglycin and related hypoglycemic compounds. Brit. Med. Bull., 25: 250 (1969).

25. Tanaka, K.: On the mode of action of hypoglycin. J. Biol. Chem., $217: 7465$ (1972).

26. Tanaka, K., Isselbacher, K. J., and Shih, V.: Isovaleric and $\alpha$-methylbutric acidemias induced by hypoglycin A: Mechanism of Jamaican vomiting sickness. Science, 175: 69 (1972).

27. Tanaka, K., Miller, E. M., and Isselbacher, K. J.: Hypoglycin A: A specific inhibitor of isovaleryl CoA dehydrogenase. Proc. Natl. Acad. Sci. U. S. A., 68: 20 (1971).

28. Trauner, D. A., David, R. B., Madge, G., Brown, R. E., and Mamunes, P.: Reye's syndrome and free-fatty acid induced coma (Abstract). Pediat. Res., 6: 329 (1972).

29. Williamson, J. R., Fukami, M. T., Peterson, S. G., Rostand, S. G., and Scholz, R.: Effect of 4-pentenoic acid on coenzyme A metabolites in rat liver. Biochem. Biophys. Res. Commun., 36: 407 (1969).

30. Purina Rat Chow, Ralston Purina Co., St. Louis, Mo.

31. Research Organic/Inorganic Chemical Co., Sun Valley, Calif.

32. Model PHM 72 Radiometer, Copenhagen, Denmark.

33. Hyland Division, Travenol Laboratories, Inc., Costa Mesa, Calif.

34. This work was presented in part at the Society for Pediatric Research Meeting, May, 1974.

35. Requests for reprints should be addressed to: A. M. Glasgow, M.D., Department of Pediatrics, University of Colorado Medical Center, 4200 E. Ninth Ave., Denver, Colo. 80220 (USA).

36. Accepted for publication November 12, 1974. 